\title{
EM CONTATO COM A VIOLÊNCIA - OS PROFISSIONAIS DE SAÚDE E SEUS PACIENTES VÍTIMAS DE MAUS TRATOS
}

\author{
Marlene Braz* \\ Maria Helena C.A. Cardoso*
} BRAZ, M.; CARDOSO, M.H.C.A. Em contato com a violência- os profissionais de saúde e seus pacientes vítimas de
maus tratos. Rev.latino-am.enfermagem, Ribeirão Preto, v. 8, n. 1, p. 91-97, janeiro 2000.

Utilizando-se de uma abordagem qualitativa, esse artigo delineia a percepção de profissionais de saúde, sobretudo pediatras, acerca da violência e sua responsabilidade em denunciar os casos que vivenciaram. Embora tratando-se de um estudo de caso - a experiência no Instituto Fernandes Figueira/FIOCRUZ - a preocupação é a de fornecer material para a reflexão acerca do posicionamento frente à morbidade infantil por "causas externas", traçando sugestões para uma práticalação que ponha em pauta a articulação entre violência e assistência à saúde da criança.

UNITERMOS: violência, responsabilidade legal, assistência à saúde, cultura, sociedades, saúde infantil

\section{INTRODUÇÃO}

A análise dos dados referentes à morbidade infantil no Brasil aponta, de forma clara e irrefutável, para a ampliação assustadora do que se convencionou chamar de "causas externas".

Diversos pesquisadores têm reunido esforços no sentido de sistematizar a questão da violência, apontando com precisão as dificuldades em se delimitar sua relação com as dimensões da morbidade (MINAYO, 1994). A estreita ligação entre violência e saúde pública, explicitada nas crianças e adolescentes vítimas de maus tratos, mas subregistrada em função da baixa quantidade de serviços de atendimento a estes e suas famílias (DESLANDES, 1994) torna premente a união de forças para a reflexão em torno de como enfrentar o problema.

Nesse sentido, decidiu-se abordar as percepções e a experiência revivida de profissionais de saúde especificamente pediatras ligados à chefia de ambulatórios, enfermarias e departamentos voltados à assistência à saúde da criança - integrantes do corpo médico do Instituto Fernandes Figueira da Fundação Oswaldo Cruz, diante do que eles próprios nomeiam como "casos de violência", enfocando-se, prioritariamente, o senso de responsabilidade profissional face à violência cometida contra crianças. Este recorte de médicos pediatras, em postos de chefia, responde exatamente à problemática da responsabilidade conforme ressaltada no Estatuto da Criança e do Adolescente, o que será abordado, neste artigo, antes de passar-se aos resultados da análise dos dados coletados em campo.

Sendo um hospital terciário, de alta capacitação técnica, o Instituto Fernandes Figueira não poderia manter-se à margem dessa discussão, até porque, o nível de sua atuação assistencial demanda que o silêncio seja quebrado e a ação, transcendendo o ato da cura, torne-se preventiva e participativa.

\section{METODOLOGIA EMPREGADA}

O material foi coletado por meio de entrevistas, perfazendo um total de 10 depoimentos, com média de duas horas de gravação cada.

Todos os entrevistados registraram, em fita cassete, consentimento livre e esclarecido em participar do estudo, manifestando a satisfação em integrar o projeto assim como a anuência com os objetivos e a metodologia proposta. Nenhum deles requisitou modificações posteriores, assim como não houve qualquer manifestação de desistência ou de desagrado às questões prospostas.

Da mesma maneira, os autores contaram com o apoio da direção do Instituto Fernandes Figueira/ FIOCRUZ não só no que tangeu à realização da pesquisa, como também quanto a sua divulgação em congressos e reuniões científicas, notadamente, o X Congresso LatinoAmericano de Psiquiatria e o I Congresso Brasileiro de Ciências Sociais em Saúde, ambos realizados na cidade

* Pós Graduação em Saúde da Criança e da Mulher do Departamento de Ensino do Instituto Fernandes Figueira da Fundação Oswaldo Cruz. Avenida Rui Barbosa 716, 5o andar, Rio de Janeiro, RJ, 22250-020, Brasil 
de Curitiba no decorrer de 1995, quando a investigação começava a dar os seus primeiros resultados.

Os depoimentos foram trabalhados como narrativas conversadas, que é a maneira pela qual GRELE (1985) conceitua a chamada história oral. Para ele a entrevista oral é composta por três estruturas, uma interna e duas externas, que lhes são subjacentes. A primeira delas, a lingüística, refere-se ao quadro de relações emergentes entre cada som, palavra ou signo articulados para criar a forma gramatical ou literária da entrevista; a segunda, performática, baseia-se na interação dialética entre entrevistador e entrevistado e as premissas sociais, psicológicas e culturais, hábitos, percepções e códigos que cada um traz à narrativa e, finalmente, a terceira, cognitiva, contém as relações que emergem dentro da entrevista entre o sujeito e a informação que está prestando. Dentro dessa perspectiva, o testemunho oral produzido remete-se a uma forma de conversação onde não há conflito ou concordância, mas sim a argumentação e o consenso de que a discussão, da questão em pauta, por si própria, merece ser mantida. Também se processa uma narrativização cujo eixo principal reside no fato de que o entrecruzamento do mito, da ideolologia e da história na constituição da visão do vivido é complexo, contudo, o modo como é formulado, mediante os esforços conjuntos das partes envolvidas, como se desenvolve numa narrativa, é passível de ser analisado e descrito.

A coleta do material, portanto, tornou-se uma atividade conjunta, organizada e informada pelas perspectivas históricas dos pesquisadores e depoentes, e, para se estudar o conteúdo discursivo combinou-se uma análise das relações sócio-culturais e psicológicas dos entrevistados com o tema, confrontando-a com a observação participante e uma contínua busca de sinais emitidos pelo silêncio e pelo explicitamente não dito. Para atingir esse objetivo, operacionalizou-se o paradigma indiciário com base no método proposto por Morelli (GINZBURG, 1989), atentando-se para o que tal método tem de comum com a semiótica médica e a história da psicanálise.

A escolha pela história oral também se baseou no entendimento de que o mapeamento das percepções buscadas, passava pelo agenciamento da memória e pela história de cada um, pois aqueles que são entrevistados, assim como quem entrevista, possuem uma compreensão, acerca de qualquer aspecto temático proposto, permeada por ideologias que se constróem desde cedo e emergem a partir de experiências culturais vividas cotidianamente. A articulação histórica se faz necessária, portanto, para permitir dimensionar a questão ideológica nos quadros formais de uma pesquisa, sem perder-se de perspectiva os perigos e os limites que ela impõe.
Na pesquisa em questão, operacionalizou-se não somente o relato ou a descrição dos casos lembrados, mas a percepção pessoal da violência, a partir da premissa de que os profissionais médicos entrevistados inseremse dentro das fronteiras de uma determinada cultura. As ideologias e os enfoques individuais foram analisados dentro do enquadramento conceitual de cultura comum à sociologia contemporânea, isto é, entendendo-a enquanto o sistema de significações através do qual, sem excessão, uma certa ordem social é comunicada, vivenciada e estudada (WILLIAMS, 1992).

Baixo esse olhar, a violência remete a todos para o sentido da vida nos nossos tempos. Este, por sua vez, determina uma espécie de consciência confusa da historicidade humana (HELLER, 1993), em função da perplexidade despertada pela constatação de que a cultura, historicamente produzida, ofertou as ferramentas para a maior das violências: o próprio extermínio.

O homem torna-se objeto da violência e da força e para de encará-las como fenômenos endêmicos e esporádicos de brotamento da "irracionalidade". Antigos valores normativos sofrem o embate da realidade percebida, quebram-se, são abandonados e em seu lugar estabelece-se a falta e com ela o sentimento de perda.

$\mathrm{E}$, a questão da violência e da responsabilidade perante ela patenteia-se ainda mais sofrida e ameaçadora quando relacionada ao que a cultura emblematizou como o futuro: a criança.

\section{REFLEXÕES SOBRE RESPONSABILIDADE}

A responsabilidade do profissional frente à violência pode ser discutida em dois aspectos principais: o jurídico e o da consciência moral. Periodizar-se-á, aqui, o segundo.

Antes, porém, faz-se preciso abrir um parêntese em relação ao primeiro aspecto, uma vez que, de saída, no concernente à responsabilidade, ele deixa uma importante questão em aberto.

$O$ Estatuto da Criança e do Adolescente (BRASIL, Leis, Decretos, 1990), Lei no 8.069 de julho de 1990, dispõe:

"Art. 13. Os casos de suspeita ou confirmação de maus tratos contra criança ou adolescentes serão obrigatoriamente comunicados ao Conselho Tutelar da respectiva localidade, sem prejuizo de outras providências legais.

Art. 245. Deixar o médico, professor ou responsável por estabelecimento de atenção à saúde e de ensino fundamental, pré-escola 
ou creche, de comunicar à autoridade competente os casos de que tenha conhecimento, envolvendo suspeita ou confirmação de maus tratos contra a criança ou adolescente:

Pena - multa de três a vinte salários de referência, aplicando-se o dobro em caso de reincidência".

Sendo assim, torna-se patente que se obriga qualquer cidadão a comunicar os casos de maus tratos, porém estabelece-se penalização administrativa somente para médicos, educadores e dirigentes atuantes em suas respectivas áreas.

Salienta-se, pela lei, claramente, que recai sobre o médico, dentro de uma equipe multidisciplinar de saúde, a maior responsabilidade. Só ele será punido caso não proceda a comunicação. Obviamente tal constatação deixa no ar o questionamento dos critérios de inclusão e exclusão de responsabilidades, implicando num certo enviesamento e hierarquização da cidadania. Se todos são obrigados, por que apenas o médico deverá ser institucionalmente punido?

Este parêntese/interlúdio remete diretamente, por via da reflexão, ao aspecto que metodologicamente escolheu-se enfatizar e que, por sua vez, encontra-se articulado diretamente à ética e a moral.

No Novo Dicionário da Língua Portuguesa (FERREIRA, 1975), os dois termos são assim conceituados:

Ética: estudo dos juízos de apreciação referentes à conduta humana suscetível de qualificação do ponto de vista do bem e do mal, seja relativamente à determinada sociedade, seja de modo absoluto.

Moral: conjunto de regras de conduta consideradas, quer de modo absoluto para qualquer tempo ou lugar, quer para grupo ou pessoa determinada.

Apesar de banalmente utilizados como sinônimos, na realidade, a "palavra ética ficou reservada à designação da ciência moral, enquanto que moral designa o fato moral, determinando as leis da conduta humana" (FERRAZ, 1994, p.16).

Ambos os termos, contudo, parecem não dar conta da responsabilidade imputada ao médico frente a uma criança vítima de violência, uma vez que abarcam um juízo de valor sobre o que seria certo ou errado de um modo mais objetivante, facilitando o próprio sujeito sentir-se à parte ou funcionando como mero espectador.

O conceito que talvez ilumine mais proficuamente a questão não passa pela penalização e nem por abstrações, mas toca de perto cada um em sua respectiva subjetividade. É o da consciência moral, que deve ser entendida como a faculdade que se tem de fazer distinção entre o bem e o mal, de onde resulta o sentimento do dever ou da proibição de se cometer certos atos, e a aprovação ou a dor de consciência por tê-los executado (FERREIRA, 1975).

Para se chegar a ter consciência moral faz-se necessário introjetar os valores éticos e morais aceitos como tais na cultura que se produz e vivência. Aquilo que pode ser visualizado nos fins do século XX enquanto imoral ou anti-ético, por exemplo, não o era na Grécia antiga onde a escravidão era natural e o escravo não era considerado um ser humano, mas um instrumento. A ética e a moral estão inseridas dentro de um tempo e de um espaço humano em mutação. São, por conseqüência, dotadas de historicidade.

Sob a ótica da psicanálise a consciência moral pode ser vista como uma faculdade do aparato psíquico responsável por estabelecer juízos de valor sobre os atos que se pratica, dos quais podem advir satisfação ou sentimento de remorso, de acordo com a anuência ou discordância da ação que se executa em relação a eles (FERRAZ, 1994).

A responsabilidade, então, de cada um está ligada aos valores éticos da sociedade na qual se vive e da qual se faz uma leitura crítica a partir dos respectivos desenvolvimento e história de vida. Este é o fator que marcará as diferenças no agir e pensar pessoais e, muitas vezes, uma dicotomia entre eles.

Segundo Kohlberg, citado por FERRAZ (1994), a criança teria dois tipos de moralidade: a moralidade heteronômica ou moralidade de repressão e a moralidade de cooperação. A primeira vigoraria em crianças de até oito anos de idade, quando ela é a parte mais fraca e o adulto seu superior. Ela se expressaria pela idéia de uma responsabilidade colocada no exterior, em regras rígidas e imutáveis, num valor absoluto em que o dever é visto como submissão ao mais velho, sendo que a transgressão é sinal de punição. Nela há um desconhecimento de reciprocidade, a justiça sendo expiatória e a responsabilidade atribuída ao coletivo. A segunda, a partir dos oito anos, é caracterizada pela autonomia e o respeito mútuo. Ela se revelaria por uma responsabilidade subjetiva, intenção, as regras não sendo mais imutáveis e, sim, flexíveis. O valor é relativizado, sendo o juízo de valor elaborado sem levar em conta as punições. A noção do dever começa a ser sentida em função da expectativa do outro: há a idéia de reciprocidade, a noção de justiça é retitutiva e a responsabilidade é vista como individual.

A maturidade, de acordo com os postulados da psicanálise, adviria da passagem de um funcionamento mental regido pelo princípio do prazer para um regido pelo princípio da realidade. No entanto, restará sempre uma pulsão que se rebela contra o princípio da realidade e que, portanto, questiona em seu cerne a concepção de maturidade e com ela a de responsabilidade.

Estas questões, contudo, não foram suficientemente pesquisadas tendo em vista a temática 
da violência. De um modo geral, pode-se afirmar que mesmo nos campos mais eruditos as divergências são inúmeras, todavia podendo ser resumidas em três grandes teses: a primeira advoga que a agressividade é inerente ao indivíduo; a segunda defende que a sociedade é a responsável pelos males existentes em função da exclusão social imposta pelo capitalismo globalizado e, finalmente, a terceira postula a complexificação do tema, mostrando que a realidade não é tão simples, já que a violência perpassa os mais diferentes setores das classes sociais, ocorrendo entre ricos e pobres e, muitas vezes, inexistindo em pessoas ou grupos que tiveram suas vidas marcadas por maus tratos e agressões cotidianas.

\section{O QUE AS FALAS "DIZEM"}

Para a equipe médica entrevistada, a violência possui várias graduações e tipologias. Porém, basicamente assenta-se sobre o explícito (maus tratos infligidos ao corpo) e o sutil (agravos ao bom desenvolvimento psíquico e à cidadania).

O primeiro termo do binômio é considerado óbvio e marca a memória de forma contundente. Nele situam-se os casos espontânea e inicialmente narrados e que demonstram despertar o sentimento de responsabilidade civil.

De maneira consensual, todos os entrevistados apontam fraturas múltiplas, traumatismo craniano e marcas difusas de queimaduras, justificadas pelos pais enquanto fruto de acidentes, como indícios de maus tratos. Entretanto, mesmo diante de tais evidências, o procedimento habitual é, por força da formação, requisitar uma série de exames complementares. Tais sinais, portanto, não são valorizados de imediato, como evidências de agressões ou maus tratos. Um dos entrevistados diz: "face a uma criança portadora de hematomas pede-se exames de sangue para saber se apresenta discrasia sangüinea”.

É somente após ser afastada exaustivamente a hipótese orgânica, mesmo diante de suspeitas compartilhadas por toda a equipe, que se volta para as "causas externas". O primeiro caminho para a investigação e verificação é sempre o da discussão entre a equipe. A este se segue a ação propriamente dita, quase sempre compreendendo várias conversas com os acompanhantes da criança; pedidos de ajuda à equipe de saúde mental ou ao serviço social; comunicação à direção do hospital; tentativa de encaminhamento a alguma organização não governamental e em casos considerados mais graves - os realmente confirmados - à autoridade judiciária competente.

Todos foram unânimes em afirmar que mesmo quando a suspeita é forte, freqüentemente nada é feito a não ser perguntar aos responsáveis, às vezes de forma contundente e incisiva, como tal fato se deu, tentando pegá-los em contradição, já que dificilmente ocorre a confissão espontânea. Acontecendo a negação peremptória o caso é dado por encerrado.

Em certas ocasiões, quando a criança é internada em função de uma doença orgânica e apresenta lesões corporais indicadoras de maus tratos é bastante difícil, diz um terço dos entrevistados, firmar o diagnóstico de violência, uma vez que há o temor de se cometer injustiças. Desejando-se lançar mão da ótica psicanalítica poder-se-ia levantar a hipótese desse temor corresponder a um manifesto mecanismo de defesa: a negação. A par da questão da formação médica que privilegia uma etiologia orgânico patogênica das lesões, ocorreria uma tendência a negar que as afeções não correlatas à doença de base e classicamente relacionadas a maus tratos, pudessem ser conseqüência de atos de violência corporal. Obviamente quando isso ocorre, de acordo com os relatos, dificilmente uma providência é tomada.

Tendo ou não encaminhado o caso, o sentimento final, invariavelmente, é o de frustração ou impotência. De forma geral se reivindica do poder público, policial e/ou judiciário, a solução para o problema. Dois entrevistados asseveraram enfaticamente que quando acontece do médico decidir fazer uma queixa crime é, na maioria das vezes, aconselhado pela autoridade policial a desistir. Se, por ventura, consegue levar a cabo a sua queixa não é chamado a depor ou testemunhar, o que leva à conclusão inevitável de que o processo foi arquivado. O pouco consolo que resta, dizem eles, é saber que o fato de já haver um registro poderá facilitar o estabelecimento de um processo futuro, caso ocorra reincidência.

Quando há a recorrência a instituições não governamentais, os testemunhos coletados evidenciam que os representantes destas não aparecem para dar encaminhamento ao caso, restringindo-se meramente a solicitar que os pais ou responsáveis compareçam no endereço da entidade ou a sugerir ao médico chefe da equipe que comunique o fato ao Juizado de Menores. Tais soluções, no entender dos depoentes, não conduzem a lugar algum. No primeiro caso, segundo eles, os pais não comparecem e, no segundo, verbalizam o temor do juiz retirar a guarda da criança, colocando-a numa instituição onde é capaz de sofrer agressões ainda mais graves.

Todos os médicos entrevistados tiveram em algum momento contato com crianças vítimas de violência. Todos tentaram alguma solução e nenhuma foi satisfatória, culminando por impor-se a imobilidade. Esta imobilidade é reconhecida por uma metade como de ordem pessoal e, por outra como de caráter institucional. 
No fim, afirmam: predomina o estático. Um dos médicos entrevistados, quando questionado sobre o que fez diante dos casos confirmados de violência, respondeu: "Literalmente nada, embora eu quisesse fazer muito". Esta não é uma resposta singular. Na verdade, ela sintetiza muito bem todas as posições analisadas.

O sentimento que resta é o da impotência. Assistindo clinicamente a criança ou o adolescente, são obrigados a dar-lhes alta e entregá-los de volta aos responsáveis, ignorando o que futuro trará. Marcados por essas experiências, lembram-se de cada uma delas com detalhes, mesmo quando aconteceram no passado distante. Apesar de não explicitarem, sentem-se causadores de um mal, co-responsáveis por não poderem agir fora do âmbito de seu ofício, mesmo porque quando o fazem, nada resulta. A consciência moral provoca uma tensão perceptível em todos os entrevistados, acompanhada de angústia, indignação, revolta e culpa.

O que adjetivamos de sutil, o segundo termo do binômio, relaciona-se com o domínio do não visível, daquilo que está para além da configuração corpórea ou radiográfica da violência. A racionalização qualifica esse tipo de dano quanto tão ou mais grave do que a agressão física. Considera-se a vítima também um caso característico de "maus tratos em pediatria", conforme categoriza um dos depoentes.

O interessante é que são casos unanimemente correlacionados à experiência na clínica privada $\mathrm{e}$ estimados como de difícil constatação. São sempre imputados ao posicionamento dos pais e exemplificados pela ausência paterna quando há a separação do casal; pela idealização dos fillhos levando a cobranças como a de bom desempenho escolar ou a de comer bem, quando a própria fase de desenvolvimento infantil não requer a ingestão de grande quantidade de alimentos; pelo privilegiamento de um filho em detrimento do outro, quer por questões projetivas, quer por questões de gênero: o menino mais bem cuidado do que a irmã e assim por diante.

Outro fator predominante no "dizer" das falas é a dificuldade de intervenção junto à clientela do setor privado. Divididos quanto a problemática dos maus tratos relacionados às crianças socialmente mais privilegiadas, nenhum narrou qualquer caso de processo contra esta clientela, verbalizando, inclusive, a posição delicada em que ficam para indicar um tratamento psicológico para os pais.

Analiticamente, podemos dizer que por trás de tal postura existe a noção de que o homem vive em comunidade e esta estrutura-se com a divisão de poderes entre a maioria mais poderosa do que o indivíduo per si. A LEI surge como passo inicial à constituição de um viver socialmente feliz, na medida em que fiscaliza e ordena o conflito; sem ela reinaria o instintual e a vida comunitária seria impossibilitada (FREUD, 1981). Esta divisão de poderes, no concernente aos discursos, se reflete na oposição pais-adultos poderosos versus filhoscriança frágeis.

A violência psicológica, apesar de percebida, não é tão valorizada quanto a física e apresenta-se separada desta, reforçando a dicotomia entre corpo e mente. Parece que esta forma de mau trato é entendida enquanto não ameaçadora da integridade física da criança e, assim sendo, passível de não ser enfatizada. Bater na criança, colocá-la de castigo, privando-a das coisas de que mais gosta são atos vistos enquanto componentes do educar. Todos de algum modo já lançaram mão destes recursos. Educar é dar limites, contudo é difícil estabelecer os limites dos limites, dada a subjetividade com a qual se revestem.

Nesse ponto a situação complica-se, pois, toda e qualquer forma de educação pressupõe violência e, de alguma forma, medir qualitativamente a extensão da fronteira entre o educar e o infligir maus tratos torna-se difícil. Esse fator, possivelmente, é um dos que explica a valorização dos casos levados a internamento, ou seja: o maior impacto do explícito sobre o sutil.

Por outro lado, não menos importante, estão os profissionais de saúde mental. Estes tendem a silenciar sobre a violência. Sua formação implica em compreender e tratar os agressores e, assim, não consideram como sua responsabilidade a denúncia. Entretanto, a maior parte das crianças encaminhadas para tratamento psicológico revelam as marcas de maus tratos, físicos e psíquicos. Dentre os últimos é freqüente, por exemplo, a rejeição encoberta pela superproteção ou pela permissividade.

Ao mesmo tempo que os programas de prevenção à violência solicitam que os agressores sejam denunciados há a demanda para que sejam compreendidos. Os profissionais de saúde mental, na qualidade de cidadãos, precisam discutir este aparente paradoxo, até para melhor situar seu locus de atuação, participação e responsabilidade dentro de uma equipe multidisciplinar. É necessário reconhecer que para denunciar um fato é preciso se indignar com ele. A compreensão não pode ser escudo da omissão.

Pode-se afirmar também que o binômio explícito/ sutil compõe uma mesma melodia, quando adentramos no tópico da violência enquanto efeito das paixões individuais ou conseqüência de questões sociais. A melodia, contudo, tem compassos dissonantes estabelecendo uma clara divisão entre o individual e o social. Os discursos até aqui, mais ou menos uniformes, repartem-se. Cerca de 1/3 dos entrevistados assume uma posição, dir-se-ía, mais sociológica. Os restantes assimilam a norma hobbesiana de "o homem é lobo do homem". As experiências pessoais de submissão aos ditames da comunidade, cuja célula mater é a família, 
fazem a trilha sonora à racionalização discursiva, quer no sentido mais socialista de imputar à sociedade a culpa pela violência, quer no sentido mais neo-liberal de imputá-la ao indivíduo, porém colocando-o enquanto dotado de uma função societária.

O público e o privado entram em cena, com o segundo estabelecendo sinonímia com a posse de boa qualidade de vida e, o primeiro articulando-se à idéia de pobreza. Novamente, a racionalização dita um discurso abrangente sobre a problemática em questão, assegurando que os dois termos do binômio encontram-se em ambos os setores. Todavia, como já indicado, através do relato de casos, evidencia-se uma cristalina relação de causalidade entre população pobre e violência explícita e classes médias e altas e violência sutil.

Diante desse conflito a responsabilidade no encaminhamento dos "casos de violência" se dicotomiza e o enfrentamento da questão é, no setor público, considerado mais seguro. Nele nunca se está sozinho. Há uma instituição municipal, estadual ou federal funcionando como âncora e o indivíduo transita sua intervenção mediado pela esfera pública. Nesse caso, a responsabilidade pessoal é ungida de uma função supraindividual, ou seja, social (WERNECK VIANNA, 1978). Uma resposta símbolo desta discussão é a que se segue: "Eu acho que é diferente, porque no setor privado o nivel de diálogo é outro. Você vai conversar mais sobre os aspectos psíquicos que levaram aquilo. Você fica menos preocupado com as questões legais".

Falindo a mediação pública, o senso de responsabilidade social não desaparece e a reminiscência dá vida ao sentimento perante os infligidores das agressões: a raiva. A raiva não é uma categoria utilizada pelos pesquisadores para exprimir o sentir coletivo. Ela é o nome da coisa, no caso, a emoção, utilizado por todos os entrevistados para exteriorizar suas reações. No dizer de DEWEY: "Uma pessoa normal não presenciará um ato de desusada crueldade sem imediata reação de desaprovação; sobrevêm, imediatamente, ressentimento e indignação" (1981, p.283).

Um especialista em neurolingüística diria que estamos diante da união entre linguagem e fala (LOCKE, 1995). A linguagem seria um instrumento de representação dos pensamentos e a fala nossa capacidade de comunicar esta representação. Para os pesquisadores, contudo, apresenta-se a hipótese de que essa representação da emoção pensada revela, antes de tudo, a insuficiência de meios para regular as relações humanas na família, no Estado e na sociedade (FREUD, 1981). E a ela agrega-se a consciência confusa de historicidade aludida anteriormente.
A ordem jurídica foi composta e é produto do viver em comunidade constituinte de nossa cultura. Entretanto, vemô-la falhar e a culpamos. Mas culpá-la não seria um meio de fugir do sofrimento imposto pela responsabilidade?

\section{CONSIDERAÇÕES FINAIS}

Diante do exposto, afirma-se que as marcas do explícito e do sutil, que cada qual carrega dentro de si, postas em confronto com aquelas dos outros conduzem ao reviver de situações dolorosas. Em cada uma dessas situações, um dos alicerces de nossa cultura global - o amor - sofre ameaças e abalos. Corrobora-se a sensação de que a renúncia aos instintos, sob o império da necessidade, não traz a recompensa sonhada. Resta a decepção. E esta para ser recalcada exige a fuga ou a paralisia. Culpabiliza-se os mecanismos que a "sociedade" fabricou para tentar a felicidade comum. A cultura se transforma na mãe/madrasta e nós nos paralisamos frente a violência com que ela nos trata.

Nesse trabalho assume-se que a sociedade não transcende os atores históricos e é ela que lhes impõe regras e normas de conduta cuja transgressão é passível de punição. A sociedade é feita pelos homens. São eles que, pelo menos nos regimes de democracia representativa, elegem seus representantes, e, dentro dos pressupostos de liberdade de pensamento, palavra e ação, concordam que determinados atos são ilegais, imorais ou anti-éticos.

A discussão sobre indivíduo e sociedade, subjacente a todos os pontos levantados, é longa e ainda não solucionável. No entanto cabe enfatizar que posicionamentos imbricados em determinismos, sejam eles de qualquer ordem, podem resvalar para a tentação reducionista que em nada ajudará o enfrentamento de uma questão tão mobilizante quanto a violência.

De tudo que foi dito nas "narrativas conversas", de todos os conflitos, ambigüidades, ideologias, hábitos, formações, códigos, comportamentos, medos, mitos, sonhos, raiva... emerge a conclusão de que se for possível estabelecer uma relação com a criança na qual não se atualize e banalize a violência; se for possível saber ouvir e conduzir, dentro da sobrecarga da realidade das agressões sofridas, sem pressões, chantagens, silêncios reticentes, indiferença, julgamentos precipitados, culpabilizações..., poder-se-á atuar como amortecedores, diminuindo a extensão daquilo que a expressão "causas externas" de morbidade infantil açambarca**.

\footnotetext{
** As autoras agradecem à prof. Graça Pizá T. Menezes sua prestimosa colaboração e à Ana Beatriz Braz de Almeida que participou da pesquisa na qualidade de bolsista de iniciação científica (Fiocruz/Faperj)
} 
IN CONTACT WITH THE VIOLENCE - THE HEALTH CARE PROFESSIONALS AND THEIR PATIENTS VICTIMS OF ABUSE

Using qualitative methods of collecting data and analysis, this article outlines the way health care profissionals, mainly pediatricians, feel about violence and their responsibility in denouncing the cases which they were forced to deal with. Although a typical "case study" - the experience in Instituto Fernandes Figueira/FIOCRUZ - the major concern of this work is to offer material for reflexion about procedures that should or could be taken in face to child morbidity caused by "external causes", making suggestions for a health conduct that enhances the relationship between violence and the medical practice related to child and adolescent abuse.

KEY WORDS: violence, legal liability, medical assistance, culture, societies, infant health

\section{EN CONTACTO CON LA VIOLENCIA - LOS PROFESIONALES DE LA SALUD Y SUS PACIENTES VÍCTIMAS DE MALOS TRATOS}

Valiéndose de un abordaje cualitativo, este artículo traza la percepción de los profesionales de la salud, sobre todo pediatras, acerca de la violencia y la responsabilidad de ellos para denunciar los casos que se les presentan día a día. Apesar de tratarse de un estudio de caso -la experiencia en el Instituto Fernandes Figueira/FIOCRUZ - la preocupación es la de proporcionar material para la reflexión sobre el posicionamento frente a la morbilidad infantil por "causas externas", dando sugerencias para una prácticalacción que ponga en discusión la articulación entre violencia y atención de la salud del niño.

TÉRMINOS CLAVES: violencia, responsabilad, atención a la salud, cultura, sociedades, salud del niño

\section{REFERÊNCIAS BIBLIOGRÁFICAS}

01. BRASIL. Leis, Decretos. Lei no2 8069 de 13 de julho de 1990. Dispõe sobre o Estatuto da Criança e do Adolescente, e dá outras providências. Diário Oficial da União, Brasília, 1990. Título II, Capítulo I \& Título VII, Capítulo II.

02. DESLANDES, S.F. Atenção a crianças e adolescentes vítimas de violência doméstica: análise de um serviço. Cadernos de Saúde Pública, v.10, p. 177-187, 1994. Supl. 1.

03. DEWEY, J. Teoria da vida moral. In: DEWEY, J. Os pensadores. São Paulo: Abril Cultural, 1981.

04. FERRAZ, F.C. A eternidade da maça: Freud e a ética. São Paulo: Ed. Escuta, 1994.

05. FERREIRA, A.B.H. Novo dicionário da língua portuguesa. Rio de Janeiro: Nova Fronteira, 1975.

06. FREUD, S. Il malestar en la cultura. In: FREUD, S. Obras completas. 4. ed. Madrid: Editorial Biblioteca Nueva, 1981. Tomo 3.
07. GINZBURG, C. Mitos, emblemas, sinais: morfologia e história. São Paulo: Companhia das Letras, 1989.

08. GRELE, R.J. Envelops of sound: the art of oral history. Chicago: Precedent Publishing, 1985.

09. HELLER, A. Uma teoria da história. Rio de Janeiro: Civilização Brasileira, 1993.

10. LOCKE, J.E. O aprendizado da censura. Folha de São Paulo, São Paulo, Caderno 5, 9 de abril de 1995.

11. MINAYO, M.C. de S. A violência social sob a perspectiva da saúde pública. Cadernos de Saúde Pública, Rio de Janeiro, v. 10, p. 7-18, 1994. Supl. 1.

12. WERNECK VIANNA, L.J. Liberalismo e sindicato no Brasil. 2. ed. Rio de Janeiro: Paz e Terra, 1978.

13. WILliAMS, R. Cultura. São Paulo: Paz e Terra, 1992. 